\title{
Índice de Inovação: hierarquização dos produtores do arranjo produtivo local de fruticultura irrigada, estado do Ceará
}

\author{
Kilmer Coelho Campos ${ }^{1}$ \\ Fátima Marília Andrade de Carvalho ${ }^{2,3}$
}

Resumo: Enquadrou-se a proposta de identificar e analisar grupos homogêneos de produtores com diferentes níveis produtivos e inovativos, possibilitando seu melhor desenvolvimento no arranjo produtivo local de fruticultura irrigada localizado nos municípios de Limoeiro do Norte e Russas, no estado do Ceará. Utilizou-se a técnica de análise fatorial para a definição dos fatores e a análise de agrupamentos para a formação dos grupos homogêneos. Constatou-se que o desenvolvimento do arranjo produtivo local de fruticultura irrigada da microrregião do Baixo Jaguaribe no estado do Ceará é sustentado por um grupo de produtores mais integrados e intensivos nos processos de produção, inovação, cooperação e aprendizado interativo e pelas relações desenvolvidas em termos locais.

Palavras-chave: Índice de inovação, Arranjo produtivo local, Fruticultura irrigada, Ceará.

Abstract: The proposal is to identify and analyze homogeneous groups of producers with different productive and innovations levels, to develop better in the arrangement productive horticulture place irrigated located in the Limoeiro do Norte and Russas cities, in Ceará state. The technical of factorial analysis was used for the definition of the factors and the analysis of groupings to form homogeneous groups. The development

1 Doutor em Economia Aplicada pela UFV-MG e professor adjunto da UFC. E-mail: kilmercc@bol.com.br

2 Professora do curso de Mestrado Profissionalizante em Administração do Centro Universitário UMA, Belo Horizonte (MG). E-mail: fmacarvalho2010@gmail.com

3 Este trabalho baseia-se na tese de conclusão do curso de doutorado em Economia Aplicada da UFV-MG, realizada pelo primeiro autor do artigo e orientada pelo segundo autor. 
Índice de Inovação: hierarquização dos produtores do arranjo produtivo local de fruticultura irrigada, estado do Ceará

of the arrangement productive place of irrigated horticulture of Low Jaguaribe in Ceará state is sustained by a group of producers which are more integrated and intensive in the production processes, innovation, cooperation and interactive learning, and for the relationships developed in local terms.

Key-words: Innovation index, Local arrangement productive, Irrigated horticulture, Ceará.

Classificação JEL: C38; R10.

\section{Introdução}

No Nordeste, as atividades agropecuárias são desenvolvidas basicamente por agricultores familiares, pois, segundo estudo do Incra/FAO (2000), a região concentra o maior número de estabelecimentos familiares do Brasil. Especificamente para o Ceará, os estabelecimentos familiares representam 90,2\% do total de 339,6 mil, detêm 52,9\% da área total de 8,99 milhões de hectares e são responsáveis por $52,2 \%$ do valor bruto da produção agropecuária. Além disso, $84,1 \%$ dos estabelecimentos familiares empregam apenas mão de obra familiar em suas atividades (INCRA/FAO, 2000).

A renda proveniente das atividades agropecuárias é também muito baixa, pois, dos 149.506 estabelecimentos familiares da categoria "proprietários de terra", 70.846, ou 47,4\%, enquadram-se na tipologia de "quase sem renda", que compreende aqueles agricultores com renda total por hectare/ano de $\mathrm{R} \$ 23,00$. Em ordem crescente, listam-se os de "renda baixa", em número de 32.122, ou $21,5 \%$, que perfazem renda de $\mathrm{R} \$ 62,00$ por hectare/ano, os de "renda média", que somam 34.376 , ou $23 \%$, e renda de $R \$ 76,00 /$ hectare/ano e, por fim, os de "maiores rendas", que são 12.162 , ou $8,1 \%$, e obtêm renda média anual por hectare de R\$ 170,00 . Deve-se ressaltar que a área média desses estabelecimentos é da ordem de 13,2, 23,2, 40,4 e 77,5 ha, respectivamente (INCRA/FAO, 2000).

Moreira Filho, Coelho e Rocha (1985) apontam o tradicionalismo das técnicas utilizadas como causa do baixo desempenho produtivo, enquanto Casimiro (1984) identifica fatores tais como a baixa fertilidade dos solos, a inadequação das tecnologias disponíveis, as irregularidades pluviométricas, a falta de recursos financeiros e de esquemas de comercialização, as arcaicas relações sociais de produção e os baixos níveis de escolaridade como fatores de entrave ao melhor desempenho das atividades produtivas.

É importante, então, identificar potencialidades regionais que resultem, por meio da implementação de políticas públicas e investimentos privados, no desenvolvimento de atividades econômicas voltadas para a produção, geração 
de emprego, renda e com elevado grau de competitividade, tanto no plano local, como nacional e internacional.

A adoção de estratégias eficientes de desenvolvimento local que apoiem a aglomeração de micro, pequenas e médias empresas ou produtores poderá contribuir para a oferta de emprego, a obtenção de renda e a diminuição de entraves que dificultam a expansão destas empresas, como o acesso ao crédito, a má operacionalização e administração do empreendimento, a mão de obra desqualificada e os elevados encargos tributários.

Assim, o estudo de arranjos produtivos locais (APL) toma nova dimensão e importância, uma vez que as micro e pequenas empresas necessitam cada vez mais de procedimentos e análises que levem em consideração aspectos como a inovação, interação, cooperação, aprendizagem e articulação de configurações institucionais, proporcionando, assim, a inserção e o desenvolvimento dessas empresas no mercado competitivo e globalizado.

Nessa perspectiva, enquadrou-se a proposta de identificar e analisar grupos homogêneos de produtores com diferentes níveis produtivos e inovativos, possibilitando seu melhor desenvolvimento no arranjo produtivo local de fruticultura irrigada localizado nos municípios de Limoeiro do Norte e Russas, no estado do Ceará. Especificamente, pretendem-se identificar fatores comuns e/ou específicos relacionados às características do perfil do produtor, produção, mercados e empregos, e também as características dos processos de inovação, cooperação e aprendizado; e localizar e agrupar os produtores homogêneos, elaborando um índice que represente o nível inovativo de cada produtor.

\section{Referencial teórico}

No Brasil, adota-se a terminologia arranjos produtivos locais, que são redes e agrupamentos localizados com produção especializada, constituídos por intermédio de manifestações espontâneas, auto-organizadas, surgidas em torno de um ponto onde se forma um núcleo produtivo, em virtude de existência de fonte de matérias-primas; presença de fornecedores; disponibilidade de recursos naturais; proximidade de mercados; presença de universidades e centros de pesquisa; bifurcações causadas por estratégias de sobrevivência de pequenos produtores submetidos à grande produção agrícola, entre outras características (AMARAL FILHO, 2002).

De acordo com Cassiolato e Lastres (2003), as principais vantagens do foco em arranjos produtivos locais referem-se à representação de uma unidade prática de investigação que vai além da tradicional visão baseada na organização individual (empresas), setor ou cadeia produtiva, permitindo estabelecer uma ponte entre o território e as atividades econômicas; a focalização num grupo de variados agentes (empresas e organizações de P\&D, educação, treinamento, 
744 - Índice de Inovação: hierarquização dos produtores do arranjo produtivo local de fruticultura irrigada, estado do Ceará

promoção, financiamento, entre outras) e atividades conexas que normalmente caracterizam qualquer sistema produtivo e inovativo local; a simbolização do locus real, onde o aprendizado ocorre, as capacitações produtivas e inovativas são criadas e fluem os conhecimentos tácitos; e a representação de um importante desdobramento da implementação das políticas de desenvolvimento industrial, particularmente daquelas que visem a estimular o aprendizado, a inovação e a criação de capacitações.

Entre os vários aspectos que caracterizam os Arranjos e Sistemas Produtivos e de Inovação Locais (ASPL), a Rede de Pesquisa em Sistemas Produtivos e Inovativos Locais (Redesist) ${ }^{4}$ menciona, como características de alçada importância, a dimensão territorial; a diversidade de atividades e agentes econômicos, políticos e sociais; a importância associada ao conhecimento tácito; a existência de processos de inovação e aprendizado interativos; e as formas de governança inerentes às relações entre diferentes segmentos de agentes (CASSIOLATO, LASTRES e SZAPIRO, 2000).

A dimensão territorial é de grande importância para o desenvolvimento de arranjos produtivos, pois define o espaço de abrangência dos processos produtivos, inovadores e cooperativos. A proximidade ou concentração geográfica de empresas ou produtores em determinada área ou região enseja o compartilhamento de visões e valores econômicos, sociais e culturais, constituindo fonte do dinamismo local e de vantagens competitivas em relação a outras regiões (ALBAGLI e BRITO, 2003).

Os arranjos produtivos locais envolvem a participação e a interação de empresas, que podem ser desde produtoras de bens e serviços finais até fornecedoras de insumos e equipamentos, prestadoras de serviços, empresas comerciais e clientes. Podem, ainda, estar representados por sindicatos, associações e cooperativas, além da participação de órgãos públicos e privados, como universidades, institutos de pesquisa, empresas de consultoria e de assistência técnica e organizações não governamentais, que desenvolvam atividades voltadas para a formação e capacitação de recursos humanos; pesquisa, desenvolvimento e engenharia; política, promoção e financiamento (ALBAGLI e BRITO, 2003).

O conhecimento tácito representa uma vantagem competitiva, pois se origina de características locais de determinadas regiões, dadas a proximi-

4 A Redesist é uma rede de pesquisa de caráter interdisciplinar, formalizada desde 1997, sediada no Instituto de Economia da Universidade Federal do Rio de Janeiro e coordenada pelos professores José Eduardo Cassiolato e Helena M. M. Lastres. Desta rede, participam diversas universidades e institutos de pesquisa no Brasil e no exterior, promovendo importantes estudos sobre o papel dos arranjos e sistemas produtivos locais (ASPL's) na elaboração do desenvolvimento econômico (http://www.redesist.ie.ufrj.br). 
dade territorial e a assimilação de identidades culturais, sociais e empresariais pelos agentes. Este conhecimento reside em crenças, valores, saber técnico e habilidades do indivíduo ou organização, incluindo o domínio de técnicas utilizadas na produção não disponíveis em acervos bibliográficos, relacionando-se a saberes gerais e comportamentais, à capacidade para resolução de problemas não codificados e à capacidade para estabelecer vínculos entre situações e interagir com outros recursos humanos (CAMPOS, 2004).

A capacidade inovativa das empresas pode ser manifestada pela ação realizada durante o processo de mudança tecnológica, representando o resultado do esforço de empresas para investir em atividades de pesquisa e desenvolvimento (P\&D) e na incorporação destes resultados, oriundos destas atividades, em novos produtos, processos e estruturas organizacionais.

Já a governança está relacionada aos diferentes modos de coordenação, intervenção e participação nos processos de decisão locais, que envolvem diversos agentes (empresas, trabalhadores, organizações) e atividades (fluxos de produção até a distribuição de bens e serviços), assim como processos de geração, transmissão e uso de conhecimentos e inovações. É importante ressaltar que as relações entre os agentes envolvidos nos arranjos produtivos são quase sempre determinadas pelos fluxos de insumos e produtos por meio de vínculos verticais ou horizontais, estabelecidos entre empresas e fornecedores ou entre empresas de um mesmo ramo (VARGAS, 2002).

\section{Metodologia}

\subsection{Identificação de fatores relacionados às características do arranjo produtivo local}

A análise fatorial tem a finalidade de analisar a estrutura das inter-relações (correlações) de grande número de variáveis, definindo um conjunto de dimensões latentes comuns (fatores). Esta análise permite o resumo e redução dos dados, encontrando fatores que, quando interpretados e compreendidos, descrevem os dados em um número muito menor de conceitos do que as variáveis originais (HAIR JR. et al., 2005).

A análise fatorial (AF), pelo método dos componentes principais, objetivou, neste estudo, reduzir ou simplificar a interpretação de uma base de dados, sem comprometer informações relevantes sobre as características do perfil dos produtores do arranjo produtivo local; características de produção, mercados e empregos gerados na estrutura produtiva do APL; e características ou traços de inovação, cooperação e aprendizado desenvolvidos no âmbito 
746 - Índice de Inovação: hierarquização dos produtores do arranjo produtivo local de fruticultura irrigada, estado do Ceará

do APL por produtores locais. Assim, com base na AF, restaram identificados fatores comuns ou específicos relacionados ao nível produtivo e inovativo dos produtores do APL.

O modelo de análise fatorial constituído com base na matriz de correlação relaciona linearmente as variáveis padronizadas e os fatores comuns desconhecidos. As equações do modelo podem ser representadas por (MINGOTI, 2005):

$$
\mathrm{Z}_{p}=1_{p 1} \mathrm{~F}_{1}+1_{p 2} \mathrm{~F}_{2}+\ldots+1_{p m} \mathrm{~F}_{m}+\varepsilon_{p}
$$

Neste modelo, $Z_{\mathrm{i}}(\mathrm{i}=1,2, \ldots, \mathrm{p})$ são variáveis originais padronizadas relacionadas linearmente com as novas variáveis aleatórias $F_{j}, j=1,2, \ldots, m$, que constituem fatores comuns não identificados e explicam as correlações entre as variáveis. Os coeficientes $1_{\mathrm{ij}}$ são as chamadas "cargas fatoriais" (factor loading) e representam o grau de relacionamento linear entre $Z_{\mathrm{i}}$ e $\mathrm{F}_{\mathrm{j}}$ (associação entre a variável e o fator). Os componentes $\varepsilon_{i}, i=1,2, \ldots, p$, são os erros aleatórios e correspondem aos erros de medida e à variação de $Z_{\mathrm{i}}$ que não é explicada pelos fatores comuns $\mathrm{F}_{\mathrm{j}}$ incluídos no modelo.

A análise fatorial foi realizada com suporte em 17 indicadores de perfil do produtor; produção, mercados e empregos; e inovação, cooperação e aprendizado do APL, observados em 83 produtores de frutas dos perímetros irrigados, conforme citado a seguir:

X1 - Idade do produtor proprietário (anos).

X2 - Grau de escolaridade do produtor proprietário (número).

X3 - Renda bruta anual da atividade em 2007 (R\$).

X4 - Produtividade anual da atividade em 2007 (kg/ha).

X5 - Custos anuais com mão de obra em 2007 (R\$).

X6 - Custos anuais com insumos agrícolas em 2007 (R\$).

X7 - Custos anuais com energia elétrica em 2007 (R\$).

X8 - Capital total empregado na atividade irrigada (R\$).

X9 - Quantidade de empregados na atividade em 2007 (número).

X10 - Introduções de inovações entre 2000 e 2007 (índice).

X11 - Inovações realizadas em 2007 e sua constância (índice).

X12 - Gastos realizados com inovações na atividade (R\$).

X13 - Vendas de produtos realizadas para o Brasil e exterior (R\$).

X14 - Tecnologia agrícola utilizada na atividade (número).

X15 - Treinamento desenvolvido para o produtor e/ou empregados (sim ou não).

X16 - Fontes de informação importantes para o aprendizado da atividade (índice).

X17 - Cooperação desenvolvida entre produtores e agentes locais (sim ou não). 


\subsection{Agrupamento de produtores homogêneos do arranjo produtivo local}

A análise de agrupamentos foi feita considerando-se os escores fatoriais obtidos pela análise fatorial, que utilizou os indicadores de perfil do produtor; de produção, mercados e empregos; e de inovação, cooperação e aprendizado citados anteriormente. O objetivo, com a utilização desta técnica, é identificar grupos distintos de produtores, quanto aos fatores produtivos e inovativos, dentro do arranjo produtivo, de forma a subsidiar o cálculo de um índice que represente o nível inovativo e a posterior caracterização destes grupos de produtores.

A análise de agrupamentos tem como objetivo a divisão dos elementos da amostra ou da população em grupos, de forma que elementos pertencentes a um mesmo grupo sejam similares entre si em relação às variáveis consideradas e medidas, e os elementos em grupos diferentes sejam heterogêneos em relação a estas mesmas características (MINGOTI, 2005).

A análise de agrupamento utiliza o conceito de distância entre as unidades de classificação. Entre os métodos ou medidas utilizadas para a mensuração dessa distância, utilizou-se, neste estudo, a distância euclidiana quadrada, que representa a soma dos quadrados das diferenças dos valores de todas as variáveis consideradas, expressa algebricamente por:

$$
\mathrm{d}\left(\mathrm{X}_{l}, \mathrm{X}_{k}\right)=\left[\sum_{i=1}^{p}\left(\mathrm{X}_{i l}-\mathrm{X}_{i k}\right)^{2}\right]
$$

em que os dois elementos amostrais $X_{1}$ e $X_{k}, 1 \neq k$, são comparados em cada variável pertencente ao vetor de observações. São medidas de dissimilaridade e, logo, quanto menores os seus valores, mais similares serão os elementos que estão sendo comparados (MINGOTI, 2005). Essas distâncias entre os elementos da amostra são inseridas numa matriz de distâncias (dimensão nxn), em que " $\mathrm{d}_{\mathrm{ij}}{ }^{\prime}$ constitui a distância do elemento " $\mathrm{i}$ " ao elemento " $\mathrm{j}$ ".

Considerando-se o objetivo de identificar grupos distintos de produtores, quanto aos fatores produtivos e inovativos dentro do arranjo produtivo local, utilizou-se o Método das k-Médias, que constitui um dos métodos não hierárquicos mais utilizados e conhecidos, em que cada elemento da amostra é alocado àquele cluster cujo centróide (vetor de médias da amostra) é o mais próximo do vetor de valores observados para o respectivo elemento (HARTINGAN e WONG, 1979).

No Método das k-Médias, primeiramente, escolhem-se k centróides (sementes ou protótipos), para se iniciar o processo de partição; em seguida, compara-se cada elemento da amostra com cada centróide inicial por uma medida de distância; posteriormente, recalculam-se os valores dos centróides para cada novo grupo formado e compara-se novamente cada elemento com cada novo centróide formado destes novos grupos; e, finalmente, repetem-se 
os dois passos anteriores até que todos os elementos amostrais estejam bem alocados em seus grupos.

A escolha do número final de grupos ou clusters é subjetiva e pode depender dos objetivos do pesquisador. Após a especificação e validação dos agrupamentos, classificaram-se os produtores em quatro grupos, de acordo com suas particularidades, com arrimo nos escores fatoriais. Dado que, pela análise fatorial, se identificou a presença de quatro fatores, se calculou o escore fatorial médio, obtido por meio da soma dos escores dos produtores de cada grupo, ponderado pela sua participação na renda bruta total anual (RBA) da atividade no grupo em que estão inseridos. Elaborou-se também um índice bruto, que se refere à média aritmética dos escores fatoriais médios encontrados, representando o nível de desenvolvimento de cada grupo dentro do arranjo produtivo local.

\subsection{Elaboração do Índice de Hierarquização do arranjo produtivo local}

A elaboração de índices, esteada na coleta de variáveis diversas que descrevem um fenômeno, sintetiza em única ou em poucas variáveis a informação de todas que foram medidas sobre o fenômeno. Então, com a técnica de análise fatorial, pode-se calcular e formular um índice de hierarquização que represente o nível de inovação do arranjo produtivo local, ou seja, elaborar um indicador que corresponda a um número-índice e represente o nível inovativo de cada produtor dos grupos identificados no APL, com o objetivo de identificar e analisar grupos distintos quanto às características de produção, inovação, cooperação e aprendizado.

Esse índice de inovação permite identificar um núcleo ou grupo de produtores responsável pelo desenvolvimento do APL ou que estimula as atividades de interação, cooperação e aprendizado dentro do arranjo, dinamizando as atividades produtivas e inovativas locais.

Para elaborar este índice, tomou-se como base a metodologia proposta em Rossato (2006), que estimou e formulou o Índice de Qualidade Ambiental (IQA) e o Índice de Desenvolvimento Humano-Ambiental (IDH-A) para os municípios do Rio Grande do Sul; e Soares et al. (1999), que criaram um Índice de Desenvolvimento Municipal (IDM) para os municípios do Ceará.

De acordo com Rossato (2006), este índice pode ser representado pela soma dos escores fatoriais padronizados, obtidos pela análise fatorial, ponderados pelas respectivas parcelas de explicação da variância total dos dados de cada fator. A formulação matemática é expressa como:

$$
I I_{m}=\sum_{j=1}^{k} \frac{\lambda_{j}}{\operatorname{tr}(\mathrm{R})} F_{j m}
$$


em que:

$\mathrm{II}_{\mathrm{m}}$ = Índice de Inovação do produtor " $\mathrm{m}$ " no arranjo produtivo local;

$\lambda_{\mathrm{j}}=\mathrm{j}$-ésima raiz característica da matriz de correlação $\mathrm{R}_{\mathrm{pxp}}$ das variáveis utilizadas;

$\mathrm{K}=$ número de fatores escolhidos;

$\mathrm{F}_{\mathrm{j} \mathrm{m}}=$ escore fatorial do produtor " $\mathrm{m}$ ", do fator $\mathrm{j}$;

$\mathrm{Tr}=$ traço da matriz de correlação $R_{\text {pxp. }}$.

Com a finalidade de facilitar a comparação dos índices de desempenho inovativo dos produtores do arranjo produtivo local, pode-se transformar a base dos índices, de modo que os respectivos valores sejam estimados dentro do intervalo compreendido entre 0 e 100 :

$$
I I{ }^{*}{ }_{m}=\frac{\left(I I_{m}-I I_{\min }\right)}{\left(I I_{\max }-I I_{\min }\right)} \times 100
$$

em que:

$\mathrm{II}_{\mathrm{m}}^{*}=$ Índice de Inovação transformado do produtor " $\mathrm{m}$ " no arranjo produtivo local; $\mathrm{II}_{\mathrm{m}}$ = Índice de Inovação do produtor " $\mathrm{m}$ " no arranjo produtivo local;

$\mathrm{II}_{\max }=$ Índice de Inovação máximo do arranjo produtivo local;

$\mathrm{II}_{\min }=$ Índice de Inovação mínimo do arranjo produtivo local.

Para classificar os produtores de cada grupo específico, de acordo com os índices de inovação, utilizou-se a análise de agrupamentos, pelo método das K-Médias, para as partições das classes. Optou-se por classificar os produtores de cada grupo em quatro classes de agrupamento, em que, para cada classe, tem-se: $P(j)=\left\{\Phi_{i}(j): 1<i<n_{j}\right\} ; j=1,2,3,4$.

em que:

$P(j)=$ classe de agrupamento $\mathrm{j}$;

$\Phi_{\mathrm{i}}(\mathrm{j})=$ coordenada $\mathrm{i}$ da classe $\mathrm{j}$.

Assim, o centro da classe $\mathrm{P}(\mathrm{j})$, ou seja, a média das coordenadas de seus elementos, foi denotado por $\Omega(\mathrm{j})$, e a soma de quadrados residuais dentro do j-ésimo grupo SQRes (j) foi dada por:

SQRes $(\mathrm{j})=\Sigma \mathrm{D}^{2}\left(\Phi_{\mathrm{i}}(\mathrm{j}) ; \Omega(\mathrm{j})\right) ; 1<\mathrm{i}<\mathrm{n}_{\mathrm{j}}$ em que:

$\mathrm{D}^{2}=$ quadrado da distância euclidiana do elemento $\mathrm{i}$, da classe $\mathrm{j}$ ao seu centro.

Quanto menor for este valor, mais homogêneos são os elementos (produtores) dentro de cada classe e melhor será a partição.

\subsection{Natureza, fonte dos dados e amostra}

Os dados de natureza primária foram coletados em pesquisa direta, realizada por meio de questionário que aborda esse conjunto de variáveis quantitativas e qualitativas, aplicado em entrevista junto a produtores (fruticultores). 
Índice de Inovação: hierarquização dos produtores do arranjo produtivo local de fruticultura irrigada, estado do Ceará

O questionário foi composto pela coleta de informações com os produtores do arranjo sobre suas características, aspectos relacionados à produção, mercados e emprego, processos de aprendizagem e inovação, participação dos produtores em experiências de cooperação e em programas de apoio às micro e pequenas empresas.

A pesquisa foi realizada por amostragem probabilística aleatória simples, levando-se em conta a população de produtores que exploram a fruticultura irrigada no arranjo produtivo local. Entrevistou-se uma amostra de 83 produtores extraída do público que compõe o universo da pesquisa, formado por 190 produtores que trabalham com a fruticultura irrigada no APL. O número de produtores da amostra por classe foi a seguinte: 39 micros; 21 pequenos; 21 médios e 2 grandes.

\section{Resultados e discussão}

\subsection{Resultado da análise fatorial aplicada ao arranjo produtivo local (APL)}

Com base na análise fatorial (AF), aplicada para agrupar as características de perfil dos produtores, características de produção, mercados e empregos gerados na estrutura produtiva e características ou traços de inovação, cooperação e aprendizado desenvolvidos no âmbito do APL pelos produtores locais, identificaram-se fatores comuns ou específicos relacionados ao nível de produção e inovação dos produtores do APL.

Essa análise foi realizada com base nas observações feitas para os 17 indicadores de perfil, produção e inovação do APL, observados em 83 produtores de frutas de perímetros irrigados.

Verificou-se, inicialmente, que a técnica de análise fatorial é adequada à aplicação dos dados considerados, uma vez que o teste de esfericidade de Bartlett, cujo valor obtido foi de 3.448,075, mostrou-se significativo a $1 \%$ de probabilidade, permitindo rejeitar a hipótese nula de que a matriz de correlação é uma matriz identidade, isto é, que as variáveis não são correlacionadas.

$\mathrm{O}$ teste de Kaiser-Meyer-Olkin (KMO), que mede a adequabilidade da amostra, apresentou valor de 0,854 , o que permite estabelecer adequação da análise fatorial ao conjunto de dados, ou seja, indica que os fatores encontrados explicam grande parte da associação entre as variáveis e que os resíduos apresentam fraca associação entre si. Ambos os testes realizados permitiram, assim, concluir que a amostra utilizada foi ajustada ao procedimento da análise fatorial. 
O cálculo e a comparação da matriz de correlação observada e reduzida (estimada) permitiram obter os resíduos. Com a observação dos resíduos, verificou-se que a maioria dos valores foi menor do que 0,05 , ou seja, $87 \%$ dos resíduos tinham valores menores do que 0,05 , indicando que o modelo se ajustou bem aos dados.

A análise fatorial original realizada pelo método dos componentes principais apresentou resultados de interpretação difícil, pois algumas variáveis relacionavam-se com mais de um fator. Logo, utilizou-se a transformação ortogonal dos fatores originais, que apresenta solução em que cada fator se relaciona mais claramente com determinadas variáveis. A rotação ortogonal foi feita pelo método Varimax, amplamente utilizado e que produz soluções mais simplificadas.

Conforme a Tabela 1, após a rotação ortogonal, a análise pelo método dos componentes principais permitiu identificar quatro raízes características com valores superiores a 1. Logo, para a interpretação dos resultados, optou-se por utilizar quatro fatores, levando-se em consideração a proporção significativa de $85,67 \%$ de captação da variância total das variáveis originais.

Tabela 1. Raiz característica da matriz de correlações simples e percentual de variância explicado por fator.

\begin{tabular}{lccc}
\hline \multicolumn{1}{c}{ Fatores } & $\begin{array}{c}\text { Raiz } \\
\text { característica }\end{array}$ & $\begin{array}{c}\text { Variância explicada } \\
\text { pelo fator (\%) }\end{array}$ & $\begin{array}{c}\text { Variância } \\
\text { acumulada (\%) }\end{array}$ \\
\hline F1- nível produtivo e inovativo & 8,890 & 52,295 & 52,295 \\
F2 - nível de capacitação e informação & 2,713 & 15,960 & 68,255 \\
F3 - nível tecnológico e cooperativo & 1,530 & 9,001 & 77,257 \\
F4- nível intelectual & 1,430 & 8,412 & 85,669 \\
\hline
\end{tabular}

Fonte: Resultados da pesquisa, 2007.

O primeiro fator, isto é, a combinação linear das variáveis originais que pode explicar individualmente a maior parcela da variância, captou 52,29\% desta; o segundo fator, em ordem de contribuição para a variância total, captou 15,96\%; o terceiro fator explicou $9 \%$ da variância; e o quarto fator, $8,4 \%$ da variância total dos dados. Isto é, os fatores representam ou captam uma proporção significativa da informação de variância das variáveis originais.

A Tabela 2 apresenta as cargas fatoriais e as comunalidades para os quatro fatores considerados. Para a interpretação de cada um dos fatores, foram considerados valores absolutos superiores a 0,65 para as cargas fatoriais (destacadas em negrito), como de forte associação entre o fator e o indicador. Os valores encontrados para as comunalidades avaliam a capacidade explicativa conjunta dos quatro fatores em relação aos indicadores. 
752 - Índice de Inovação: hierarquização dos produtores do arranjo produtivo local de fruticultura irrigada, estado do Ceará

Tabela 2. Cargas fatoriais após rotação ortogonal e as comunalidades.

\begin{tabular}{lccccc}
\hline \multicolumn{1}{c}{ Indicadores } & F1 & F2 & F3 & F4 & Comunalidades \\
\hline X1 - Idade & 0,103 & 0,106 & $-0,005$ & $-0,904$ & 0,839 \\
X2 - Grau de Instrução & 0,110 & 0,402 & 0,263 & 0,686 & 0,713 \\
X3 - Renda Bruta & 0,989 & 0,101 & 0,086 & $-0,013$ & 0,996 \\
X4 - Produtividade & 0,159 & $-0,016$ & 0,830 & 0,102 & 0,726 \\
X5 - Custo Mão de Obra & 0,989 & 0,094 & 0,075 & $-0,014$ & 0,994 \\
X6 - Custo Insumos & 0,980 & 0,122 & 0,103 & $-0,007$ & 0,986 \\
X7 - Custo Energia Elétrica & 0,985 & 0,115 & 0,079 & $-0,020$ & 0,990 \\
X8 - Capital Empregado & 0,978 & 0,139 & 0,079 & $-0,008$ & 0,982 \\
X9 - Número de Empregados & 0,989 & 0,103 & 0,075 & $-0,011$ & 0,994 \\
X10 - Introdução Inovações & 0,606 & 0,579 & $-0,084$ & 0,240 & 0,767 \\
X11 - Inovações 2007 & 0,833 & 0,409 & $-0,017$ & 0,153 & 0,885 \\
X12 - Gastos Inovação & 0,955 & 0,128 & 0,111 & $-0,011$ & 0,942 \\
X13 - Vendas BR-EXT & 0,988 & 0,081 & 0,074 & $-0,018$ & 0,989 \\
X14 - Tecnologia Agrícola & 0,119 & 0,581 & 0,597 & 0,069 & 0,712 \\
X15 - Treinamento & 0,114 & 0,860 & 0,002 & $-0,134$ & 0,771 \\
X16 - Informação & 0,209 & 0,748 & 0,148 & 0,159 & 0,650 \\
X17 - Cooperação & $-0,003$ & 0,549 & 0,571 & 0,038 & 0,630 \\
\hline
\end{tabular}

Legenda: F1 - nível produtivo e inovativo; F2 - nível de capacitação e informação; F3 - nível tecnológico e cooperativo; F4 - nível intelectual.

Fonte: Resultados da pesquisa (2007).

As cargas fatoriais destacadas apresentaram correlações fortes entre os fatores e as variáveis. Alguns indicadores, contudo, apresentaram correlação moderada, como por exemplo os indicadores de introdução de inovações, tecnologia agrícola e cooperação. $\mathrm{O}$ indicador introdução de inovações apresentou correlação de 0,606 com o Fator 1 e de 0,579 com o Fator 2; mas, ao considerar o valor de maior associação e mais próximo a 0,65, classifica-se este indicador no Fator 1.

Analisando-se o indicador de tecnologia agrícola, observa-se que este possui correlação de 0,581 com o Fator 2 e de 0,597 com o Fator 3, sendo, portanto, classificado no Fator 3, que corresponde ao maior valor de associação e mais próximo do valor 0,65 (valor de forte associação). $\mathrm{O}$ indicador de cooperação apresentou correlação de 0,549 com o Fator 2 e de 0,571 com o Fator 3, sendo classificado no Fator 3, em virtude do maior valor de associação com este fator.

Os resultados revelam que o primeiro fator explica maior parcela da variância total e que os fatores (F1, F2, F3 e F4) captam ou explicam satisfatoriamente todas as variáveis, apresentando valores altos e positivos.

Percebe-se que o Fator 1 (F1), que representa 52,3\% da variância total, está positiva e fortemente relacionado com os indicadores renda bruta dos produtores (X3), custos de mão de obra (X5), custos de insumos (X6), custos de energia elétrica $(X 7)$, capital empregado na atividade (X8), número de empregados (X9), 
inovações realizadas em 2007 (X11), gastos realizados com inovações (X12) e vendas realizadas para o Brasil e Exterior (X13). O indicador de introdução de inovações (X10) está positiva e moderadamente relacionado com o Fator 1.

Estes indicadores expressam variáveis relacionadas à produção agrícola irrigada (rendas, custos de produção, mercados e empregos), valoração do capital empregado na atividade e inovações (tipos, constância e gastos) desenvolvidas para a fruticultura irrigada. Assim, a natureza dos indicadores que se relacionam com o Fator 1 indica que este representa um indicador do nível produtivo e inovativo dos produtores do APL.

O Fator 2 (F2), que representa $15,96 \%$ da variância total, está positiva e fortemente relacionado com os indicadores de treinamento (X15) e de informação (X16), que expressam variáveis relacionadas ao nível de capacitação e informação dos recursos humanos que interagem na fruticultura irrigada. Logo, a natureza dos indicadores que se relacionam com F2 indicam que este representa o indicador do nível de capacitação e informação dos produtores do APL.

O Fator 3 (F3), que representa $9 \%$ da variância total, está positiva e fortemente relacionado com o indicador de produtividade (X4), e positiva e moderadamente relacionado com os indicadores de tecnologia agrícola (X14) e de cooperação (X17). Estas variáveis expressam a produtividade dos produtores, as práticas ou técnicas agrícolas utilizadas na atividade e o nível de cooperação entre produtores e agentes locais (instituições, órgãos e empresas). Estes indicadores relacionados com F3 representam o indicador do nível tecnológico e cooperativo dos produtores do APL.

O Fator 4 (F4), que representa $8,4 \%$ da variância total, está negativa e fortemente relacionado com o indicador de idade (X1), e positiva e fortemente relacionado com o indicador de grau de instrução (X2). Estas variáveis representam a idade dos proprietários e produtores e o nível de instrução (escolaridade). $\mathrm{O}$ valor negativo elevado para o indicador idade mostra que o APL apresenta grande percentual de produtores com idades mais elevadas, ou seja, idades compreendidas entre 30 e 50 anos, conforme constatado na caracterização do APL. A correlação negativa entre este indicador (idade) e o fator pode ser justificada pelo fato de que nem sempre produtores com maior idade apresentam maior nível intelectual. Estes indicadores relacionados com F4 representam o indicador do nível intelectual (perfil) dos produtores do APL.

Assim, as 17 variáveis representativas na análise fatorial foram condensadas em quatro fatores: nível produtivo e inovativo (F1), nível de capacitação e informação (F2), nível tecnológico e cooperativo (F3) e nível intelectual (F4) dos produtores do APL.

Com esteio nas cargas fatoriais, foram determinados os escores fatoriais, ou seja, o valor dos fatores para cada unidade de produção (produtor). Esses escores foram utilizados para agrupar os produtores em grupos homogêneos. 
754 - Índice de Inovação: hierarquização dos produtores do arranjo produtivo local de fruticultura irrigada, estado do Ceará

Analisando-se os escores fatoriais dos produtores para o Fator 1, identificou-se o fato de que, do total de 83 produtores, 24 apresentaram valores positivos e 59 , valores negativos, mostrando que apenas $28,92 \%$ dos produtores apresentaram nível produtivo e inovativo acima da média. O maior escore encontrado foi 8,90747, correspondente a um grande produtor, e o menor escore foi -0,43978, relacionado a um pequeno produtor.

Considerando-seoFator2, observou-sesituaçãosemelhanteaoFator1,emque, do total de produtores, apenas 27 unidades de observação apresentaram valores positivos, ou seja, 32,53\% dos entrevistados, demonstrando que uma pequena parcela de produtores apresenta nível de capacitação e informação acima da média no desenvolvimento de agricultura irrigada, isto é, que participaram de treinamentos, cursos, seminários e palestras, buscando conhecimento teórico e prático sobre fruticultura em diversas fontes de informação, internas e externas. O maior e menor escores encontrados foram 2,84086 e -1,15994, representados por um médio e um microprodutor, respectivamente.

Já a análise dos escores fatoriais dos produtores para o Fator 3 mostrou que 42 agricultores $(50,6 \%)$ possuem valores positivos, ou seja, metade dos produtores tem nível tecnológico e cooperativo acima da média. O maior escore encontrado foi 4,91448, correspondente a um médio produtor, e o menor escore foi -2,21816, relacionado também a um médio produtor.

O nível tecnológico adequado retrata a utilização de várias técnicas ou práticas agrícolas, tais como a utilização de sementes ou mudas selecionadas e de espaçamento recomendado tecnicamente para o plantio, a realização de preparo do solo mecanizado, a realização de análise de solo em laboratórios, a utilização de adubo químico e/ou orgânico, a realização de capina mecanizada ou química, a aplicação de defensivos agrícolas, assistência técnica por agrônomo ou técnico agrícola, a retirada de restos culturais após a colheita e a realização de correção do solo. O nível cooperativo adequado envolve a participação de produtores em atividades formais e/ou informais de parcerias com outros produtores ou com agentes locais, que podem ser representados por órgãos federais, estaduais e municipais de apoio e promoção, empresas locais (fornecedoras de insumos, consultoria, entre outros) e institutos de pesquisa e centros de capacitação tecnológica do APL.

Considerando-se o Fator 4, do total de produtores, 46 unidades de observação apresentam valores positivos, ou seja, $55,42 \%$ dos entrevistados exibem adequado indicador de perfil (características pessoais), isto é, apresentam adequado nível de escolaridade e experiência na atividade e possuem idade entre 30 e 50 anos. O maior e o menor escores encontrados foram 1,68175 e $-2,56547$, representados por microprodutores.

Então, foram identificados, com base na $\mathrm{AF}$, fatores que captam uma proporção significativa da variância total contida nas informações das variáveis originais, tais como nível produtivo e inovativo (F1), nível de capacitação 
e informação (F2), nível tecnológico e cooperativo (F3) e nível intelectual (F4) dos produtores do APL.

Os escores fatoriais de cada produtor para os fatores retratam a situação do produtor em relação à média da amostra. Assim, para o Fator 1, identificou-se que apenas $28,92 \%$ dos produtores apresentaram nível produtivo e inovativo acima da média; para o Fator 2, apenas 32,53\% mostraram nível de capacitação e informação acima da média no desenvolvimento de agricultura irrigada; para o Fator 3, 50,6\% dos produtores têm nível tecnológico e cooperativo acima da média: e para o Fator 4, 55,42\% apresentaram um adequado nível de escolaridade e experiência na atividade.

Conclui-se que os produtores apresentaram como características de maior destaque (acima da média) um adequado nível tecnológico, cooperativo e intelectual dentro do APL de fruticultura irrigada.

\subsection{Agrupamento de produtores homogêneos do APL}

A análise de agrupamento mostrou que o melhor método de classificação dos grupos seria o método não hierárquico, por meio da técnica das k-médias (k-means), que apresentou melhores resultados e distribuição dos grupos. Portanto, com a finalidade de preservar características próprias dos agrupamentos, foram considerados quatro grupos distintos de produtores homogêneos.

Analisando-se a Tabela 3, constatou-se que os Grupos 1, 2, 3 e 4 são formados por 21, 1, 4 e 57 produtores, respectivamente. O Grupo 1 apresenta mais da metade dos produtores $(52,38 \%)$, classificados como médios, mas também é formado por micro $(23,81 \%)$, pequenos $(19,05 \%)$ e grandes produtores $(4,76 \%)$. O Grupo 2 possui apenas um produtor, representado pelo maior produtor do APL (grande produtor). O Grupo 3 apresenta maior percentual (75\%) de médios produtores. Já o Grupo 4 tem composição semelhante ao Grupo 1 em termos de diversificação de produtores, mas possui características de um grupo tipicamente constituído de micros e pequenos produtores.

Tabela 3. Composição dos grupos homogêneos do APL.

\begin{tabular}{ccccccccc}
\hline \multirow{2}{*}{ Grupos } & \multicolumn{2}{c}{ Micro } & \multicolumn{2}{c}{ Pequeno } & \multicolumn{2}{c}{ Médio } & \multicolumn{2}{c}{ Grande } \\
\cline { 2 - 8 } & Total & $\%$ & Total & $\%$ & Total & $\%$ & Total & $\%$ \\
\hline 1 & 05 & 23,81 & 04 & 19,05 & 11 & 52,38 & 01 & 4,76 \\
2 & 00 & 0,00 & 00 & 0,00 & 00 & 0,00 & 01 & 100,00 \\
3 & 00 & 0,00 & 01 & 25,00 & 03 & 75,00 & 00 & 0,00 \\
4 & 34 & 59,65 & 16 & 28,07 & 07 & 12,28 & 00 & 0,00 \\
\hline
\end{tabular}

Legenda: Grupo 1 - intensivo em relação ao F2 - nível de capacitação e informação; Grupo 2 - maior desempenho para o F1 - nível produtivo e inovativo; Grupo 3 - alta performance em relação ao F3 - nível tecnológico e cooperativo; Grupo 4 - desempenho moderado para os F3 - nível tecnológico e cooperativo e F4 - nível intelectual.

Fonte: Dados da pesquisa (2007). 
756 - Índice de Inovação: hierarquização dos produtores do arranjo produtivo local de fruticultura irrigada, estado do Ceará

Conclui-se que os Grupos 1 e 4 podem ser considerados mistos, mas são tipicamente caracterizados por médios e pequenos produtores, respectivamente. Já os Grupos 2 e 3 são compostos por grandes e médios produtores. O porte dos produtores dentro de cada grupo fornece uma visão preliminar do perfil característico destes aglomerados.

Após a formação dos grupos, traçou-se o perfil deles e foram calculados os escores fatoriais médios de cada um. Pelos dados, observa-se que todos os grupos apresentam o maior percentual de produtores com idade acima de 30 anos. Os Grupos 1 e 3 mostram composição de 66,66\% e 75\% dos produtores com idade acima de 41 anos. O Grupo 2 exibe produtor com idade acima de 50 anos. O Grupo 4 possui 35,09\% dos produtores com idade entre 31 e 40 anos e $54,39 \%$, acima de 40 anos.

Com relação à escolaridade, $42,86 \%$ e $100 \%$ dos produtores do Grupo 1 e 2 têm nível superior, enquanto 35,09\% dos produtores do Grupo 4 possuem curso primário. Os produtores do Grupo 3, ou seja, 75\% têm escolaridade distribuída entre os cursos primário, secundário e superior, enquanto $25 \%$ não sabem ler nem escrever.

Constata-se que os grupos apresentam, em sua maioria, produtores com idade acima de 30 anos e com níveis de escolaridade de curso primário, secundário e superior. Logo, quanto às características de idade e escolaridade, os grupos são bastante homogêneos.

Na Tabela 4, o grupo que apresenta maior renda bruta média da atividade é o Grupo 2, formado pelo maior produtor do APL, seguido pelos Grupos 1 e 3 , constituídos, em sua maioria, por médios e grandes produtores. O Grupo 4 traz menor renda bruta média da atividade, constituído, em sua maioria, por micros e pequenos produtores. A produtividade média é maior nos Grupos 3 e 2 , seguidos pelos Grupos 1 e 4. Já o montante de capital empregado na atividade é maior para os Grupos 2 e 1.

Tabela 4. Renda bruta, produtividade e valor do capital empregado dos grupos de produtores do APL de fruticultura irrigada, 2007.

\begin{tabular}{ccccccc}
\hline \multirow{2}{*}{ Grupos } & \multicolumn{2}{c}{ Renda Bruta (R\$) } & \multicolumn{2}{c}{ Produtividade $\mathbf{( k g / h a )}$} & \multicolumn{2}{c}{ Valor do Capital (R\$) } \\
\cline { 2 - 6 } & Total & Média & Total & Média & Total & Média \\
\hline 1 & 3.784 .275 & 180.204 & 442.247 & 21.059 & 4.598 .000 & 218.952 \\
2 & 14.059 .040 & 14.059 .040 & 48.670 & 48.670 & 8.400 .000 & 8.400 .000 \\
3 & 351.000 & 87.750 & 277.000 & 69.250 & 240.000 & 60.000 \\
4 & 2.286 .495 & 40.114 & 887.534 & 15.571 & 4.546 .000 & 79.754 \\
\hline
\end{tabular}

Legenda: Grupo 1 - intensivo em relação ao F2 - nível de capacitação e informação; Grupo 2 - maior desempenho para o F1 - nível produtivo e inovativo; Grupo 3 - alta performance em relação ao F3 - nível tecnológico e cooperativo; Grupo 4 - desempenho moderado para os F3 - nível tecnológico e cooperativo e F4 - nível intelectual.

Fonte: Dados da pesquisa (2007). 
O Grupo 2 se destaca pela maior renda bruta média e valor do capital empregado na atividade, tendo como principais produtos a banana e o mamão. O Grupo 1 assume a segunda colocação, relatando também renda bruta média e capital investido bem superior aos outros grupos; entretanto, o Grupo 3 mostrou melhor desempenho produtivo.

Analisando-se a Tabela 5, os custos com mão de obra permanente e temporária, insumos agrícolas (sementes, mudas, fertilizantes, defensivos, entre outros) e energia elétrica, percebe-se que os Grupos 2 e 1 apresentam custos maiores para o desenvolvimento da atividade. Os Grupos 3 e 4 possuem menor montante de custos na atividade, mas o Grupo 4, que é formado predominantemente por micros e pequenos produtores, possui gasto médio de energia elétrica maior do que o do Grupo 3, formado basicamente por médios produtores.

Tabela 5. Custos de mão de obra, insumos agrícolas e energia elétrica dos grupos de produtores do APL de fruticultura irrigada, 2007.

\begin{tabular}{ccccccc}
\hline \multirow{2}{*}{ Grupos } & \multicolumn{2}{c}{ Mão de Obra $\mathbf{( R \$ )}$} & \multicolumn{2}{c}{ Insumos $\mathbf{( R \mathbf { ~ }}$} & \multicolumn{2}{c}{ Energia Elétrica (R\$) } \\
\cline { 2 - 7 } & Total & Média & Total & Média & Total & Média \\
\hline 1 & 718.898 & 34.233 & 779.351 & 37.112 & 372.012 & 17.715 \\
2 & 3.536 .496 & 3.536 .496 & 1.863 .600 & 1.863 .600 & 1.008 .000 & 1.008 .000 \\
3 & 51.120 & 12.780 & 66.500 & 16.625 & 13.500 & 3.375 \\
4 & 426.758 & 7.487 & 359.033 & 6.299 & 243.082 & 4.265 \\
\hline
\end{tabular}

Legenda: Grupo 1 - intensivo em relação ao F2 - nível de capacitação e informação; Grupo 2 - maior desempenho para o F1 - nível produtivo e inovativo; Grupo 3 - alta performance em relação ao F3 - nível tecnológico e cooperativo; Grupo 4 - desempenho moderado para os F3 - nível tecnológico e cooperativo e F4 - nível intelectual.

Fonte: Dados da pesquisa (2007).

A presença de custos maiores para os Grupos 2 e 1 justifica-se pelo maior tamanho dos lotes produtivos e maiores investimentos diretos em mão de obra e insumos agrícolas necessários para a fruticultura. O Grupo 4 apresenta maior custo médio de energia do que o do Grupo 3 em razão do uso irracional e incorreto da irrigação, pois alguns produtores ligam o sistema de bombeamento de água em horários inapropriados, elevando a tarifa de energia elétrica.

$\mathrm{Na}$ Tabela 6, observam-se os indicadores relacionados a inovações desenvolvidas na fruticultura irrigada. Quanto à introdução de inovações de produtos e processos realizadas entre 2000 e 2007, e aquelas realizadas rotineira ou ocasionalmente durante o ano de 2007, percebe-se que apenas os Grupos 1 e 2, em sua maioria, desenvolveram estas inovações. Os gastos com as atividades inovativas também foram relevantes para os produtores dos Grupos 1 e 2. Já os Grupos 3 e 4 praticamente não apresentaram gastos com inovações para a atividade. 
758 - Índice de Inovação: hierarquização dos produtores do arranjo produtivo local de fruticultura irrigada, estado do Ceará

Tabela 6. Introdução de inovações entre 2000 e 2007, tipos e constância das inovações em 2007 e gastos com inovações dos grupos de produtores do

APL de fruticultura irrigada, 2007.

\begin{tabular}{ccccccc}
\hline \multirow{2}{*}{ Grupos } & \multicolumn{2}{c}{$\begin{array}{c}\text { Introdução de inovações } \\
\mathbf{2 0 0 0 - 2 0 0 7}(\mathbf{\%})\end{array}$} & \multicolumn{2}{c}{$\begin{array}{c}\text { Inovações realizadas em } \\
\text { 2007 (\%) }\end{array}$} & \multicolumn{2}{c}{$\begin{array}{c}\text { Gastos com inovações } \\
\text { (R\$) }\end{array}$} \\
\cline { 2 - 7 } & Sim & Não & Sim & Não & Total & Média \\
\hline 1 & 61,90 & 38,10 & 47,62 & 52,38 & 217.907 & 10.377 \\
2 & 100,00 & 0,00 & 100,00 & 0,00 & 421.771 & 421.771 \\
3 & 0,00 & 100,00 & 0,00 & 100,00 & 0,00 & 0,00 \\
4 & 14,03 & 85,97 & 8,77 & 91,23 & 25.611 & 449 \\
Total & - & - & - & - & 665.289 & - \\
\hline
\end{tabular}

Legenda: Grupo 1 - intensivo em relação ao F2 - nível de capacitação e informação; Grupo 2 - maior desempenho para o F1 - nível produtivo e inovativo; Grupo 3 - alta performance em relação ao F3 - nível tecnológico e cooperativo; Grupo 4 - desempenho moderado para os F3 - nível tecnológico e cooperativo e F4 - nível intelectual.

Fonte: Dados da pesquisa (2007).

As inovações de produtos e processos decorrem de produtores com maior visão de futuro e renda bruta e capital empregado na atividade irrigada. Portanto, os produtores dos Grupos 2 e 1 direcionaram maiores investimentos de capital para a fruticultura, aplicando parte desses recursos em inovações. Já os produtores dos Grupos 3 e 4, menores investidores na atividade, praticamente não implantaram inovações ou melhorias na empresa rural.

No que se refere ao número de empregados, os Grupos 1 e 2, constituídos por médios e grandes produtores, possuem maior número, e apresentam também maior montante de vendas de produtos para o Brasil e o exterior. Quanto às técnicas ou práticas agrícolas utilizadas na atividade irrigada, percebe-se que os Grupos 2 e 3 destacam-se como aqueles que realizam o maior número de técnicas recomendadas. De um total de 10 técnicas agrícolas alternativas, os Grupos 2 e 3 utilizam, respectivamente, dez e nove práticas em suas atividades, o que pode ser considerado um nível tecnológico avançado. Já os Grupos 1 e 4 apresentaram médias respectivas de sete e cinco técnicas agrícolas (Tabela 7). 
Tabela 7. Número de empregados, vendas realizadas para o Brasil e exterior em 2007 e técnicas agrícolas dos grupos de produtores do APL de fruticultura irrigada, 2007.

\begin{tabular}{cccccc}
\hline \multirow{2}{*}{ Grupos } & \multirow{2}{*}{ Número de Empregados } & \multicolumn{2}{c}{$\begin{array}{c}\text { Vendas para Brasil e exterior em } \\
\text { 2007 (R\$) }\end{array}$} & $\begin{array}{c}\text { Técnicas } \\
\text { Agrícolas } \\
\text { (Média) }\end{array}$ \\
\cline { 2 - 5 } & Total & Média & Total & Média & (1,33 \\
\hline 1 & 181 & 8,62 & 855.374 & 40.732 & 70,00 \\
2 & 600 & 600 & 8.013 .653 & 8.013 .653 & 8,50 \\
3 & 18 & 4,50 & 0,00 & 0,00 & 4,61 \\
4 & 191 & 3,35 & 18.000 & 316 & - \\
Total & 990 & - & 8.887 .027 & - & - \\
\hline
\end{tabular}

Legenda: Grupo 1 - intensivo em relação ao F2 - nível de capacitação e informação; Grupo 2 - maior desempenho para o F1 - nível produtivo e inovativo; Grupo 3 - alta performance em relação ao F3 - nível tecnológico e cooperativo; Grupo 4 - desempenho moderado para os F3 - nível tecnológico e cooperativo e F4 - nível intelectual.

Fonte: Dados da pesquisa (2007).

Como os Grupos 2 e 1 são constituídos basicamente por médios e grandes produtores, que detêm maior área agrícola irrigada, há maior necessidade de mão de obra para desenvolver a atividade. Estes grupos também se destacam em relação às vendas externas em função das práticas de comercialização utilizadas, da maior diferenciação de produtos comercializados no mercado e realização de técnicas agrícolas e inovações adequadas para a atividade. Os níveis tecnológicos dos Grupos 2 e 1 confirmam melhor desempenho, em termos de renda bruta média, produtividade média e inovações da atividade, apresentado por produtores destes grupos.

Os indicadores de capacitação de recursos humanos, nível e fontes de informação para o aprendizado na atividade e o desenvolvimento de atividades cooperativas ou de parcerias entre produtores e agentes locais também são de grande importância para o desenvolvimento do APL. Observa-se que, basicamente, apenas os produtores dos Grupos 1 e 2 se capacitaram ou desenvolveram treinamento para seus empregados por meio de cursos, seminários e palestras.

Quanto à busca de informações importantes para o aprimoramento da atividade, todos os produtores procuraram alguma fonte de informação, seja pelo próprio aprendizado na produção ou consultas a fontes externas, tais como empresas locais, centros de capacitação profissional e assistência técnica, participação em feiras e congressos, consultas a revistas especializadas, internet, entre outros.

Os Grupos 1, 2 e 3 desenvolveram atividades de cooperação ou parcerias com outros produtores ou agentes locais, como venda conjunta de produtos, comercialização por outro produtor, compra conjunta de insumos agrícolas, parceria de manutenção do perímetro com órgãos de apoio ao APL, entre outros. 
Índice de Inovação: hierarquização dos produtores do arranjo produtivo local de fruticultura irrigada, estado do Ceará

Já no Grupo 4, formado basicamente por micros e pequenos produtores, mais da metade não participa de atividades cooperativas.

Constatou-se que os Grupos 1 e 2 demonstram maior preocupação com a formação e aperfeiçoamento de seus recursos humanos, pois capital humano qualificado reflete o desempenho da atividade. Todos os grupos buscam algum tipo de informação para aprofundar seus conhecimentos sobre fruticultura irrigada. As atividades de cooperação também são importantes instrumentos de desenvolvimento dos produtores do APL, pois facilitam os processos produtivos, de comercialização e inovativos.

Cada escore médio, colunas 2 a 5 da Tabela 8 , foi obtido por meio da soma dos escores dos produtores de cada grupo, ponderado pela sua participação na renda bruta total anual (RBA) da atividade de fruticultura irrigada no grupo em que estão inseridos. O nível de desenvolvimento de cada grupo dentro do arranjo produtivo local refere-se à média aritmética dos escores médios encontrados, que produz um índice bruto (coluna 6).

Tabela 8. Definição dos escores médios e participação percentual na renda bruta total anual da fruticultura irrigada para os grupos de produtores do APL.

\begin{tabular}{cccccccc}
\hline Grupos & F1 & F2 & F3 & F4 & $\begin{array}{c}\text { Índice } \\
\text { Bruto }\end{array}$ & $\begin{array}{c}\text { RBA da } \\
\text { Amostra (R\$) }\end{array}$ & $\begin{array}{c}\text { \% do RBA } \\
\text { da Amostra }\end{array}$ \\
\hline 1 & $-0,04$ & 1,59 & 0,17 & 0,28 & 0,50 & 3.784 .275 & 18,48 \\
2 & 8,91 & 0,56 & 0,63 & $-0,20$ & 2,47 & 14.059 .040 & 68,64 \\
3 & $-0,23$ & $-0,71$ & 2,99 & $-0,30$ & 0,44 & 351.000 & 1,71 \\
4 & $-0,08$ & $-0,35$ & 0,14 & 0,10 & $-0,05$ & 2.286 .495 & 11,16 \\
\hline
\end{tabular}

Legenda: F1- nível produtivo e inovativo; F2 - nível de capacitação e informação; F3 - nível tecnológico e cooperativo; F4 - nível intelectual.

Fonte: Resultados da pesquisa (2007).

A análise dos fatores é feita levando-se em conta que seus escores originais, quando considerados todos os produtores da amostra, são variáveis com média zero e desvio padrão igual a 1 (um). Portanto, pode-se interpretar que os escores com valores próximos a zero indicam nível médio de desenvolvimento na fruticultura irrigada, no que se refere ao significado do fator em consideração. Quanto maior em relação a zero (média) for o escore fatorial, tanto mais avançados serão os produtores do grupo em análise, assim como a atividade do APL de fruticultura irrigada.

Com tais informações, podem ser verificadas as diferenças quanto ao nível de desenvolvimento entre os grupos formados. O Grupo 1 foi constituído por 21 produtores e responde por 18,48\% da renda bruta total anual da atividade de fruticultura irrigada da amostra. Esse grupo apresentou valor positivo bem acima da média para o fator relacionado ao nível de capacitação e informação $(1,59)$, mas obteve valor negativo referente ao fator correspondente ao nível produtivo e 
inovativo (-0,04). Este grupo desenvolveu um nível de capacitação e informação acima da média de seus recursos humanos, pois todos os produtores participaram de algum treinamento (cursos, seminários, palestras) voltado para a fruticultura irrigada. Apresenta, contudo, um rendimento produtivo e inovativo abaixo da média, o que pode ser justificado pelos altos custos de mão de obra, insumos e energia elétrica.

No que se refere aos Fatores 3 e 4, o grupo apresentou valores positivos, ou seja, 0,17 para o nível tecnológico e cooperativo e 0,28 para o nível intelectual. Isto significa que o grupo apresenta excelente nível de cooperação com outros agentes locais; faz uso, em média, de sete técnicas agrícolas (do total de 10 técnicas alternativas), mas não apresenta produtividade média elevada em relação aos outros grupos. Quanto ao nível intelectual, mais da metade dos produtores tem idade acima de 41 anos, o que favorece o grau de experiência na atividade; e $42,86 \%$ têm curso superior.

O Grupo 2 foi constituído por apenas um produtor que responde por $68,64 \%$ da renda bruta total anual da amostra. Percebe-se que os fatores médios (F1, F2 e F3) deste grupo apresentaram valores positivos acima da média da amostra, ou seja, fator produtivo e inovativo 8,91, fator de capacitação e informação 0,56 e fator tecnológico e cooperativo 0,63 . Isto se justifica pelo fato de este produtor representar a base do dinamismo e do desenvolvimento do APL (empresa-âncora), com grande concentração de área irrigada; grande número de empregados; alta participação nas vendas de produtos para o Brasil e exterior (mais de 50\% das vendas totais); elevado desenvolvimento de atividades e gastos com inovações de produtos e processos tecnológicos e organizacionais, de forma rotineira e/ou ocasional.

Além disso, desenvolve periodicamente treinamentos para seus funcionários, realiza todas as técnicas agrícolas consideradas, apresenta produtividade elevada, participa de atividades de cooperação e parcerias com 48 produtores rurais e diversos órgãos de apoio e promoção, tais como Fapija, Embrapa, Centec, Sebrae, entre outros. O Fator 4 apresentou valor negativo $(-0,20)$, ou seja, abaixo da média, o que pode ser justificado pela idade avançada do proprietário e sua escolaridade, pois percebe-se uma relação inversa entre idade do proprietário (produtor) e nível de escolaridade, isto é, quanto maior a idade, menor o nível de instrução do produtor.

O Grupo 3 foi constituído por quatro produtores e responde por 1,71\% da renda bruta total anual da atividade de fruticultura irrigada da amostra. Esse grupo apresentou valor positivo bem acima da média para o fator relacionado ao nível tecnológico e cooperativo $(2,99)$, mas obteve valores negativos para os outros três fatores, correspondentes ao nível produtivo e inovativo $(-0,23)$, nível de capacitação e informação $(-0,71)$ e nível intelectual $(-0,30)$. Este grupo apresentou maior produtividade média entre os outros grupos: desenvolveu, em média, aproximadamente, nove técnicas agrícolas (de um total de 10) e 
Índice de Inovação: hierarquização dos produtores do arranjo produtivo local de fruticultura irrigada, estado do Ceará

todos os produtores estiveram envolvidos em atividades de cooperação ou parceria no APL.

O baixo nível produtivo e inovativo decorrem dos elevados custos de mão de obra, insumos e energia elétrica, quando comparados proporcionalmente com a renda bruta média; do baixo valor de capital empregado na atividade quando comparado com os outros grupos; da existência de vendas realizadas para o Brasil e exterior; e da inexistência de gastos voltados para atividades de inovações. O fraco nível de capacitação e informação ocorre pela falta de treinamento realizado por produtores e seus empregados no âmbito do APL. O nível intelectual foi abaixo da média, em razão do baixo nível de escolaridade dos agricultores, pois $25 \%$ não sabem ler nem escrever e $25 \%$ possuem apenas o curso primário.

O Grupo 4 foi constituído pelo maior número de produtores (57) e responde por $11,16 \%$ da renda bruta total anual da fruticultura irrigada da amostra. Esse grupo apresentou valores positivos acima da média para os fatores relacionados ao nível tecnológico e cooperativo $(0,14)$ e ao nivel intelectual $(0,10)$. Observa-se que os produtores deste grupo desenvolvem, em média, metade das técnicas agrícolas consideradas, ou seja, de cinco a dez técnicas agrícolas alternativas; e $47,4 \%$ dos entrevistados participam de atividades cooperativas ou de parcerias. Quanto ao nível intelectual, $10,53 \%$ e $21,05 \%$ possuem curso superior e médio, respectivamente; e $61,41 \%$ têm idade entre 31 e 50 anos, o que retrata conhecimento e/ou experiência sobre fruticultura irrigada.

Este grupo obteve valor negativo para os fatores correspondentes ao nível produtivo e inovativo $(-0,08)$ e ao nível de capacitação e informação $(-0,35)$. O rendimento produtivo e inovativo abaixo da média pode ser justificado pela baixa renda bruta média e pelos altos custos de mão de obra, insumos e energia elétrica gerados no setor produtivo. Além disso, apenas $14 \%$ dos produtores, aproximadamente, desenvolveram atividades de inovação de produtos e processos entre 2000 e 2007; somente $8,8 \%$ realizaram inovações em 2007, de forma ocasional e/ou rotineira; e os gastos com atividades de inovação foram insignificantes. Ainda, as vendas realizadas para o Brasil e exterior também foram muito baixas. O baixo nível de capacitação e informação decorre do fato de apenas 3,5\% dos produtores entrevistados participarem ou desenvolverem algum tipo de treinamento (cursos, seminários, palestras) para seus funcionários, voltado para a fruticultura irrigada.

Em síntese, o Grupo 2, constituído por apenas um grande produtor, representa o grupo de melhor desempenho e mais intensivo quanto aos indicadores analisados, principalmente em relação ao Fator 1 (nível produtivo e inovativo). Este grupo apresentou índice bruto da ordem de 2,47, ou seja, bem acima da média da amostra. Daí justifica-se a permanência de um só produtor neste grupo, haja vista que este fruticultor representa um exemplo a ser seguido no arranjo, pois participa ativamente de todos os processos 
produtivos, tecnológicos, cooperativos, inovativos e de aprendizado interativo dentro do APL.

O Fator 2 (nível de capacitação e informação) foi decisivo para classificar o Grupo 1, representado por 21 produtores (52,38\% são médios produtores), como o segundo melhor e mais intensivo grupo, com índice bruto da ordem de 0,50, também acima da média da amostra.

O Grupo 3 formado por quatro produtores (75\% são médios produtores) ficou classificado em terceiro lugar, com índice bruto igual a 0,44. O Fator 3 (nível tecnológico e cooperativo) apresentou maior peso na composição do índice bruto deste grupo.

O Grupo 4, composto por 57 produtores (em sua maioria micros e pequenos produtores), foi o menos intensivo quanto aos indicadores e com pior desempenho, apresentando índice bruto igual a -0,05, ou seja, abaixo da média da amostra, embora tenha mostrado valores positivos para dois (F3 e F4) dos quatro fatores analisados. O Fator 3 (nível tecnológico e cooperativo) e o Fator 4 (nível intelectual) possuem maior destaque para este grupo de produtores.

A validação da análise de agrupamentos foi feita pela técnica de análise discriminante, frequentemente utilizada para diferenciar populações e/ou classificar objetos em populações predefinidas, ou seja, objetiva testar a classificação prévia de um elemento (objeto) em uma população específica.

O primeiro teste realizado objetivou verificar se as médias dos fatores são estatisticamente iguais em cada grupo de produtores. Então, caso estas médias sejam iguais em cada grupo, significa que tais fatores não podem explicar a diferenciação entre os diferentes grupos de produtores constituídos, ou seja, não são capazes de discriminar os quatro grupos. Os resultados mostram que as diferenças de médias do Fator 4, nível intelectual (variáveis idade e nível de instrução), não são estatisticamente significativas ao nível de $10 \%$ de significância estatística. Em outras palavras, o nível intelectual dos grupos de produtores é semelhante. Logo, este fator não é capaz de discriminar os grupos e deve ser excluído da análise discriminante.

Após a definição dos fatores a serem utilizados na análise, foi determinada a função discriminante para os grupos de produtores. De acordo com os novos resultados, as funções discriminantes obtidas são significativas ao nível de $1 \%$ de significância. A utilização dos escores fatoriais padronizados na análise discriminante permite que os coeficientes das funções discriminantes possam ser utilizados como indicadores do poder discriminatório de cada um dos fatores. Assim, os resultados indicam que os fatores relacionados ao nível produtivo e inovativo, ao nível de capacitação e informação e ao nível tecnológico e cooperativo representam ou discriminam corretamente os grupos de produtores identificados pela análise de agrupamentos.

Outro teste realizado procurou avaliar a capacidade da função discriminante obtida em classificar corretamente os produtores dos quatro grupos, ou seja, 
764 - Índice de Inovação: hierarquização dos produtores do arranjo produtivo local de fruticultura irrigada, estado do Ceará

alocar corretamente os elementos nos seus respectivos grupos. A adequabilidade do modelo quanto à classificação foi satisfatória, pois todos os produtores estão devidamente classificados em seus respectivos grupos ou populações. Portanto, a análise de agrupamentos está corretamente especificada.

\section{3. Índice de Hierarquização do arranjo produtivo local}

Empregando-se a técnica de análise fatorial, calculou-se um índice de hierarquização que representa o nível de inovação do arranjo produtivo local, ou seja, elaborou-se um indicador, que corresponde a um número-índice e representa o nível inovativo de cada produtor dos quatro grupos identificados no APL, detectando grupos distintos quanto aos indicadores analisados, tais como nível produtivo e inovativo (F1), nível de capacitação e informação (F2), nível tecnológico e cooperativo (F3) e nível intelectual (F4) dos produtores do APL.

O índice de inovação permite identificar um núcleo ou grupo de produtores responsável pelo desenvolvimento do APL ou que estimula as atividades de interação, cooperação e aprendizado dentro do arranjo, dinamizando as atividades produtivas e inovativas locais.

Os resultados da Tabela 9 mostram que, na Classe 1 do Grupo 1, classificaram-se quatro produtores (três médios e um grande) com índice de inovação médio igual a 81,89 . Os fatores que mais favoreceram esta posição foram o nível de capacitação e informação e o nível intelectual dos produtores, representados por indicadores como treinamento e informação dos recursos humanos do APL, bem como experiência e nível de instrução do proprietário rural. Logo, a Classe 1 apresenta-se como aquela composta por produtores que obtiveram maior índice de inovação dentro do Grupo 1 do APL de fruticultura irrigada.

Tabela 9. Hierarquização do índice de inovação (I.I.) para o Grupo 1 do APL de fruticultura irrigada, segundo as classes, 2007.

\begin{tabular}{cccccc}
\hline Classes & $\begin{array}{c}\text { Índice de Inovação } \\
\text { (I.I.) }\end{array}$ & Média & $\begin{array}{c}\text { Índice de Inovação } \\
\text { Transformado (I.I*) }\end{array}$ & Média & $\begin{array}{c}\text { No de } \\
\text { Produtores }\end{array}$ \\
\hline 1 & 0,4018 a 0,6322 & 0,4735 & 73,71 a 100,00 & 81,89 & 04 \\
2 & 0,1674 a 0,3295 & 0,2622 & 46,96 a 65,46 & 57,78 & 07 \\
3 & 0,0016 a 0,1333 & 0,0464 & 28,05 a 43,08 & 33,15 & 04 \\
4 & $-0,2442$ a -0,1238 & $-0,1832$ & 0,00 a 13,73 & 6,95 & 06 \\
\hline
\end{tabular}

Legenda: Classe 1 - Índice de Inovação Ótimo; Classe 2 - Índice de Inovação Bom; Classe 3 - Índice de Inovação Regular; Classe 4 - Índice de Inovação Insuficiente.

Fonte: Resultados da pesquisa (2007).

A Classe 2 abrange sete produtores (seis médios e um pequeno) com índice médio correspondente a 57,78. O Fator 2 (nível de capacitação e informação) apresentou valores positivos elevados, ou seja, bem acima da média, ensejando 
grande destaque para os produtores desta classe. Todos apresentaram excelente nível de capacitação de seus empregados, realizada em cursos, seminários, palestras e consultas a diversas fontes de informação.

A Classe 3 agrupou quatro produtores (dois médios e dois pequenos) e apresentou índice de inovação médio igual a 33,15. Assim, como na Classe 2 , os produtores desta classe mostraram-se mais intensivos nos processos de capacitação e informação dentro do APL.

A Classe 4, com índice médio de 6,95, foi representada por seis produtores (cinco micros e um pequeno). Nela se observam os produtores com menor grau de desenvolvimento e menos intensivos do grupo. Vale ressaltar que estes produtores apresentaram valores negativos, ou seja, abaixo da média, em pelo menos dois dos quatro fatores considerados na análise. Mostram-se, contudo, ainda mais intensivos quanto ao fator (F2) relacionado ao nível de capacitação e informação dos produtores do APL.

Conclui-se que o índice de inovação (I.I.) médio do Grupo 1 foi igual a 0,1341. De um total de 21 produtores, 52,38\% apresentaram valores acima desta média e $71,43 \%$, valores positivos para o índice de inovação. Este grupo mostrou-se mais intensivo em relação ao Fator 2 (nível de capacitação e informação), que envolve indicadores relacionados ao nível de informação e capacitação ou treinamento dos recursos humanos do APL de fruticultura irrigada.

O Grupo 2, constituído por apenas um grande produtor, apresenta índice médio de inovação (I.I.) igual a 5,5877, ou seja, possui um desempenho muito elevado em relação aos outros grupos de produtores do APL. Este grupo é muito intensivo quanto ao Fator 1 (nível produtivo e inovativo), mas também apresenta desempenho satisfatório para os Fatores 2 e 3 (nível de capacitação e informação e nível tecnológico e cooperativo). Sua qualificação de grupo de maior desenvolvimento e mais intensivo no APL advém do seu dinamismo como empresa-âncora, apresentando elevada rentabilidade e produtividade agrícola e alto desenvolvimento de atividades de interação, cooperação, aprendizado e inovação dentro do arranjo.

Os resultados da Tabela 10 mostram que na Classe 1 do Grupo 3 se classificou apenas um médio produtor, com índice de inovação médio igual a 100,00. A Classe 2 abrange dois produtores (um médio e um pequeno) com índice médio correspondente a 49,49. A Classe 3 agrupa um médio produtor com índice de inovação médio correspondente a 0,00. Os fatores que mais favoreceram esta posição foram o nível tecnológico e cooperativo, representado pelos indicadores de produtividade agrícola, técnicas agrícolas utilizadas na fruticultura e atividades cooperativas; e o nível intelectual dos produtores. Assim, este grupo apresentou produtividade média bem superior aos outros grupos, aproximadamente $69.250 \mathrm{~kg} / \mathrm{ha}$; implantou, em média, nove técnicas agrícolas; e todos os produtores participaram de atividades de cooperação no APL. 
766 - Índice de Inovação: hierarquização dos produtores do arranjo produtivo local de fruticultura irrigada, estado do Ceará

Tabela 10. Hierarquização do índice de inovação (I.I.) para o Grupo 3 do APL de fruticultura irrigada, segundo as classes, 2007.

\begin{tabular}{cccccc}
\hline Classes & $\begin{array}{c}\text { Índice de Inovação } \\
\text { (I.I.) }\end{array}$ & Média & $\begin{array}{c}\text { Índice de Inovação } \\
\text { Transformado (I.I*) }\end{array}$ & Média & $\begin{array}{c}\text { № de } \\
\text { Produtores }\end{array}$ \\
\hline 1 & 0,2457 & 0,2457 & 100,00 & 100,00 & 01 \\
2 & $-0,0084$ a 0,0297 & 0,0106 & 45,39 a 53,58 & 49,49 & 02 \\
3 & $-0,2196$ & $-0,2196$ & 0,00 & 0,00 & 01 \\
\hline
\end{tabular}

Legenda: Classe 1 - Índice de Inovação Excelente; Classe 2 - Índice de Inovação Regular; Classe 4 - Índice de Inovação Insuficiente.

Fonte: Resultados da pesquisa (2007).

O índice de inovação (I.I.) médio do Grupo 3 foi igual a 0,0118. De um total de quatro produtores, metade apresentou valores acima da média do grupo. Este grupo mostrou-se ser mais intensivo em relação ao Fator 3 (nível tecnológico e cooperativo), que envolve indicadores relacionados à produtividade agrícola, técnicas agrícolas adotadas e nível de cooperação ou parceria entre agentes locais do APL de fruticultura irrigada.

Na Tabela 11, Classe 1 do Grupo 4, classificaram-se nove produtores (um micro, cinco pequenos e três médios) com índice de inovação médio igual a 80,58 . Os fatores que mais favoreceram esta posição foram o nível tecnológico e cooperativo e o nível intelectual dos produtores.

Tabela 11. Hierarquização do índice de inovação (I.I.) para o Grupo 4 do APL de fruticultura irrigada, segundo as classes, 2007.

\begin{tabular}{cccccc}
\hline Classes & $\begin{array}{c}\text { Índice de Inovação } \\
\text { (I.I.) }\end{array}$ & Média & $\begin{array}{c}\text { Índice de Inovação } \\
\text { Transformado (I.I*) }\end{array}$ & Média & $\begin{array}{c}\text { № de } \\
\text { Produtores }\end{array}$ \\
\hline 1 & $-0,0098$ a 0,1704 & 0,0551 & 69,65 a 100,00 & 80,58 & 09 \\
2 & $-0,1355$ a $-0,0259$ & $-0,0862$ & 48,49 a 66,94 & 56,79 & 15 \\
3 & $-0,2513$ a $-0,1614$ & $-0,1989$ & 28,98 a 44,12 & 37,81 & 24 \\
4 & $-0,4234$ a $-0,2662$ & $-0,3199$ & 0,00 a 26,48 & 17,43 & 09 \\
\hline
\end{tabular}

Legenda: Classe 1 - Índice de Inovação Ótimo; Classe 2 - Índice de Inovação Bom; Classe 3 - Índice de Inovação Regular; Classe 4 - Índice de Inovação Insuficiente.

Fonte: Resultados da pesquisa (2007).

A Classe 2 abrange também 15 produtores (sete micros, seis pequenos e dois médios) com índice médio correspondente a 56,79. O Fator 2 (nível de capacitação e informação) apresentou valores positivos elevados, ou seja, bem acima da média, gerando grande destaque para os produtores desta classe.

A Classe 3 agrupou 19 micros, três pequenos e dois médios produtores e apresentou índice de inovação médio igual a 37,81. Parte dos produtores desta classe (37,5\% dos entrevistados) mostrou-se mais intensiva nos processos de produção e inovação, bem como quanto ao nível intelectual. Já outra parte 
$(62,5 \%)$ mostrou maior tendência para os processos tecnológicos e cooperativos dentro do APL.

A Classe 4, com índice médio de 17,43, foi representada por nove produtores (sete micros e dois pequenos). Nesta classe, observam-se os produtores com menor grau de desenvolvimento e menos intensivos do grupo, pois apresentaram valores negativos, ou seja, abaixo da média, em pelo menos três (F2, F3 e F4) dos quatro fatores analisados. Mostram-se, contudo, ainda mais intensivos quanto ao fator (F1) relacionado ao nível de produção e inovação do APL.

O índice de inovação (I.I) médio do Grupo 4 foi igual a -0,1482. De um total de 57 produtores, $42,11 \%$ apresentaram valores acima desta média e apenas $12,28 \%$, valores positivos para o índice de inovação. No geral, este grupo mostrou-se mais intensivo em relação aos Fatores 3 (nível tecnológico e cooperativo) e 4 (nível intelectual).

Os resultados mostrados pelo índice de inovação comprovam os resultados apresentados anteriormente (fatores médios ponderados pela renda bruta anual da atividade), em que o Grupo 1 é mais intensivo em relação ao Fator 2 (nível de capacitação e informação); o Grupo 2 apresenta maior desempenho para o Fator 1 (nível produtivo e inovativo); o Grupo 3 possui alta performance em relação ao Fator 3 (nível tecnológico e cooperativo); e o Grupo 4 apresenta desempenho moderado para os Fatores 3 e 4 (nível tecnológico e cooperativo, e nível intelectual).

Portanto, os Grupos 1 e 2 constituem o núcleo responsável pelo desenvolvimento do APL, ou seja, estimulam as atividades de interação, cooperação e aprendizado dentro do arranjo, dinamizando as atividades produtivas e inovativas locais.

\section{Conclusões}

Entre as características marcantes desses grupos, menciona-se que o Grupo 1 responde por $18,48 \%$ da renda bruta total anual da atividade de fruticultura irrigada da amostra; entretanto, possui um rendimento produtivo abaixo da média da amostra, o que pode ser justificado pelos altos custos de mão de obra, insumos e energia elétrica. Já o Grupo 2 responde por $68,64 \%$ da renda bruta total anual da amostra.

Os Grupos 1 e 2 fazem uso, respectivamente, em média, de sete e 10 técnicas agrícolas (do total de 10 técnicas alternativas) e apresentaram indicadores de produtividade média da fruticultura de $21.059 \mathrm{~kg} / \mathrm{ha}$ e $48.670 \mathrm{~kg} / \mathrm{ha}$, respectivamente; ou seja, produtividade média abaixo da verificada no Grupo $3(69.250 \mathrm{~kg} / \mathrm{ha})$.

Quanto ao destino das vendas, o Grupo 1 direcionou, em média, 8,2\% e 6,8\% de seus produtos para o Brasil e exterior em 2007, enquanto o Grupo 2 
Índice de Inovação: hierarquização dos produtores do arranjo produtivo local de fruticultura irrigada, estado do Ceará

vendeu, respectivamente, $47 \%$ e $10 \%$ dos seus produtos interna e externamente no mesmo período. Entre os fatores importantes para manter a capacidade competitiva de sua empresa ou produto, foram citadas a qualidade dos insumos agrícolas, a adoção de estratégias de comercialização, a qualidade do produto e a utilização de práticas corretas de adubação das culturas.

Quanto à introdução de inovações durante o período de 2000 a 2007, no Grupo 1, 14,3\% e 61,9\% realizaram inovações de produtos e de processos tecnológicos, respectivamente, e $28,6 \%$ fizeram mudanças organizacionais na propriedade. O Grupo 2 também desenvolveu todos os tipos de inovações, entre elas, a criação de produto com coloração diferenciada de maior aceitação no mercado e a oferta de novas variedades e de um mix de produtos para atender às necessidades dos consumidores. Quanto às inovações de processo, citam-se a utilização de composto líquido na adubação e a utilização de máquinas e equipamentos modernos.

A realização de mudanças organizacionais ocorre por meio da implementação de técnicas da gestão voltadas para um manejo adequado dos produtos, utilização de consultoria direcionada para a implantação de software de planejamento rural, controle da produção e financeiro; implementação de significativas mudanças na estrutura organizacional, tais como a construção de packing-houses, tanques de compostagem líquida, estacionamento de frutas para pós-colheita. Ocorrem também mudanças significativas nos conceitos e/ou práticas de comercialização, tais como mudança na forma de embalagem dos produtos, de acordo com o tipo de mercado consumidor; da implementação de novos métodos de gerenciamento, visando atender normas de certificação internacional.

Quanto aos gastos com essas atividades de inovação, os Grupos 1 e 2 investiram, em média, $4,3 \%$ e $3 \%$ de seus rendimentos brutos de 2007, respectivamente. O Grupo 2 gastou ainda, $2 \%$ da renda bruta com atividades de pesquisa e desenvolvimento.

Todos os produtores destes grupos estiveram envolvidos em atividades de capacitação de seus recursos humanos, troca de informações e atividades de cooperação e parcerias com outros produtores e agentes locais. Estes processos ocorreram por meio de cursos, seminários e palestras sobre a cadeia produtiva de frutas, qualidade total, manejo de irrigação e planejamento e gestão rural. A cooperação ocorreu mediante compra e venda conjunta de insumos agrícolas e produtos; e parcerias na comercialização dos produtos, oferta de cursos de capacitação, assistência técnica e manutenção do perímetro por órgãos de apoio e promoção do APL.

Constatou-se que o desenvolvimento do arranjo produtivo local de fruticultura irrigada da microrregião do Baixo Jaguaribe no estado do Ceará é sustentado por um grupo de produtores mais integrados e intensivos nos processos de produção, inovação, cooperação e aprendizado interativo e pelas relações desenvolvidas em nível local. 


\section{Referências Bibliográficas}

ALBAGLI, S.; BRITO, J. Glossário de arranjos e sistemas produtivos e inovativos locais. Rio de janeiro: REDESIST, 2003. 29p.

AMARAL FILHO, J. do. É negócio ser pequeno, mas em grupo. Desenvolvimento em debate 3: painéis do desenvolvimento brasileiro - II (BNDES), dez./2002. p. 85-118.

CAMPOS, K. C. Arranjos produtivos locais: o caso da caprino-ovinocultura nos municípios de Quixadá e Quixeramobim. Fortaleza: CCA/UFC, 2004. 97p. (Dissertação de Mestrado).

CASIMIRO, L.M.C. de. Seca: momento para repensar a pobreza do Nordeste. Fortaleza: IEL - Núcleo Regional do Ceará, 1984. 64p.

CASSIOLATO, J. E; LASTRES, H.M.M. O foco em arranjos produtivos e inovativos locais de micros e pequenas empresas. In: LASTRES, H.M.M. et al. Pequena Empresa: Cooperação e Desenvolvimento Local. Rio de Janeiro: Relume Dumará, 2003. 2000. 43p.

HAIR JR., J. F.; ANDERSON, R. E.; TATHAM, R. L.; BLACK, W. C. Análise multivariada de dados. Porto Alegre: Bookman, 2005. 5a ed. 583p.

HARTIGAN, P.; WONG, M. A. A k-means clustering algorithm: algorithm AS 1366. Applied Statistics, 28, 1979. p. $126-130$.

INCRA/FAO. Novo retrato da agricultura familiar: o Brasil redescoberto. Brasília: INCRA, 2000. 74p.

LASTRES, H.; CASSIOLATO, J.; LEMOS, C.; MALDONADO, J.; VARGAS, M. Arranjos locais e capacidade inovativa em contexto crescentemente globalizado. Relatório do projeto de pesquisa apoiado pela Diretoria de Políticas Públicas do IPEA, Rio de Janeiro: IE/UFRJ, 1998.

MINGOTI, S.A. Análise de dados através de métodos de estatística multivariada: uma abordagem aplicada. Belo Horizonte: Editora: UFMG, 2005. 295p.

MOREIRA FILHO, J. de C.; COELHO, J.; ROCHA, A. B. da. Aspectos produtivos da agropecuária do Nordeste. In: BRASIL. Ministério do Interior. SUDENE. Aspectos gerais da agropecuária do Nordeste. Recife, v. 3, SUDENE, 1985. p. 13-68 (Série Projeto Nordeste, 3).

ROSSATO, M. V. Qualidade ambiental e qualidade de vida nos municípios do estado do Rio Grande do Sul. Viçosa - MG: UFV, 2006. 139p. (Tese de Doutorado). 

fruticultura irrigada, estado do Ceará

SOARES, A.C.L.G.; GOSSON, A.M.P.M.; MADEIRA, M.A.L.H.; TEIXEIRA, V.D.S. Índice de desenvolvimento municipal: hierarquização dos municípios do Ceará no ano de 1997. Revista Paranaense de Desenvolvimento. Curitiba - PR, no97, set. dez. 1999. p. 71-89.

VARGAS, M. A. Proximidade territorial, aprendizado e inovação: um estudo sobre a dimensão local de processos de capacitação inovativa em arranjos e sistemas produtivos no Brasil. Rio de Janeiro: IE/UFRJ, 2002. 256p. (Tese de Doutorado) 